\title{
Research on Influence of Piloti Ratio on Outdoor Thermal Environment in Residential Blocks in Subtropical Climate Areas
}

\author{
Tianyu $\mathrm{Xi}^{1, \mathrm{a}}$, Jianhua Ding ${ }^{2, \mathrm{~b}}$ and Hong $\mathrm{Jin}^{3, \mathrm{c}}$ \\ ${ }^{1}$ Architecture School of Harbin Institute of Technology, Harbin City, 150006, China \\ ${ }^{2}$ School of Architecture, Tsinghua University, Peking City, 100084, China \\ ${ }^{3}$ Architecture School of Harbin Institute of Technology, Harbin City, 150006, China \\ atonny_kid@126.com, ba-djh@163.com, chongjin777@sina.com
}

\begin{abstract}
Keywords: Piloti, Outdoor thermal environment, Residential blocks, Subtropical climate
Abstract. Urban Heat Island has become a popular issue in recent years due to various problems caused by environment degradations. Many researchers have done lots of efforts to optimize the outdoor environment, including simulation models, field measurement and case studies. There are few studies research on the comprehensive influence of piloti on outdoor environment. This work takes the residential blocks in Guangzhou, China, as an example, adopting coupled simulation method, which can provide high precision prediction result, researched on the influence of piloti ratio on outdoor thermal environment in subtropical climate areas, and the impact factors of outdoor thermal environment, including temperature, wind environment, mean radiant temperature were all simulated and discussed, aiming at provide systematic references for architects, urban planners, governments and people who do research work in this field.
\end{abstract}

\section{Introduction}

Urban Heat Island is now regarded as one of the most serious environmental problems, and temperature rises in major cities in the world is shown in Fig.1. In Tokyo, Japan, the increase of days in which daily minimum temperature at night-time exceeds $25^{\circ} \mathrm{C}$ (tropical night) over the past few decades is very rapid (Fig.2). The numbers of high-summer days in Tokyo have increased from about 30 days per year in 1980 to about 45 days per year in 1998 (Fig.3).
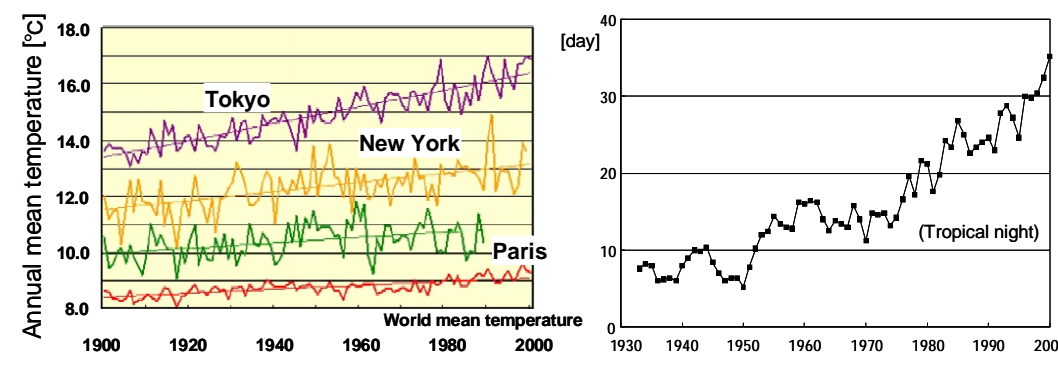

Fig.1 Temperature rises in major cities around the world
Fig.2 Number of days in which daily maximum temperature at night-time exceeds $25^{\circ} \mathrm{C}$ (Tokyo)

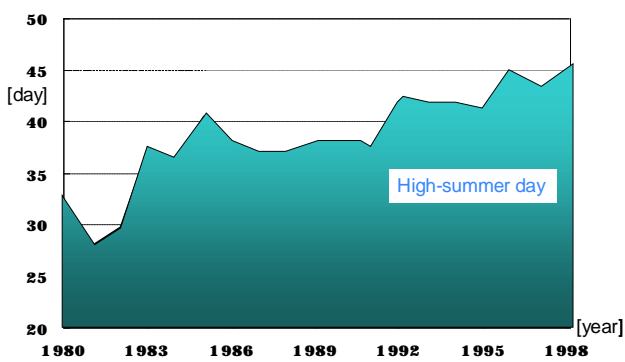

Fig.3 Number of days in which daily maximum temperature exeeds $30^{\circ} \mathrm{C}$ (Tokyo)

To reduce environmental degradation of Urban Heat Island, many researches regarding to outdoor environment are carried out, such as field measurement, simulation and wind tunnel test [1-6], but only a few work mentioned piloti's influence in the outdoor thermal environment research field, however, piloti is commonly used in building design in tropical and subtropical climate zones to gain shadow areas and good ventilation (Fig.4), thus the influence of piloti on outdoor thermal environment should be understood by designers, government and citizens.

$\mathrm{Xi}$ et al. published field measurement results of various human built elements in Guangzhou [7-10], including piloti, but no systematic analysis by simulation was used in those research. The influence of 
piloti on mean radiant temperature simulated by 3-D unsteady state heat balance radiation calculation method was published by Xi, Hong Jin et al. but no wind environment was mentioned [11,12]. Xi, Qiong Li et al. studied on the effects of semi-open space (100 percent ratio piloti) on the outdoor thermal environment of residential communities, by adopting coupled simulation method, but no different piloti ratio cases were compared [13]. Xi et al. published the comprehensive influence of piloti on outdoor wind environment in a subtropical climate city by coupled simulation method, but no other influence factors of outdoor thermal environment was mentioned [14]. This research takes residential blocks in Guangzhou, China, as an example, aiming at study on the comprehensive influence of piloti on the outdoor thermal environment, and a coupled simulation method, which offers high precision prediction result was adopted in this work.

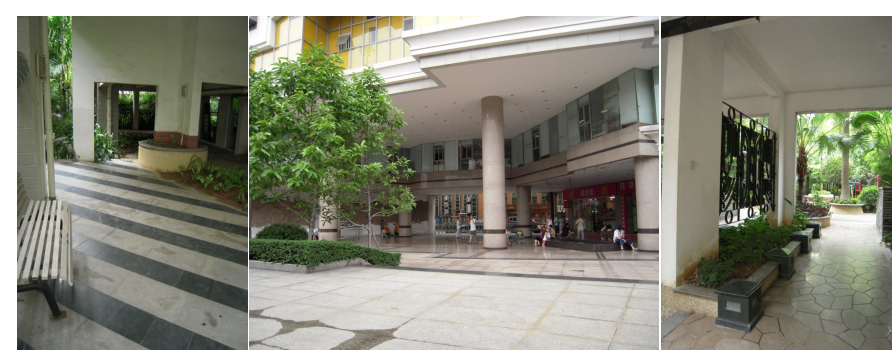

Fig. 4 Building piloti design in subtropical climate zones

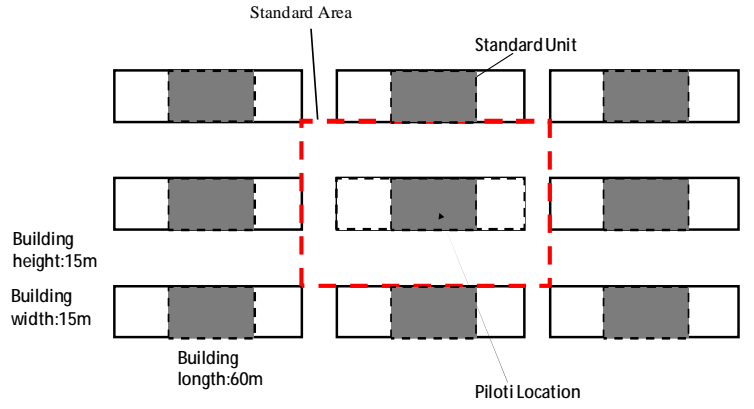

Fig.5 Standard unit and standard area

\section{Simulation Method and Case Design}

Simulation Method. The unsteady state heat balance calculation method was adopted in this paper, which includes 3-dimentional radiation and 1-dimentional conduction calculations. Firstly, non-isothermal CFD analysis is carried out in analysis using data from local meteorological bureau (wind velocity and prevailing wind direction, and air temperature) and observed data (ground and surface temperature). And ground and building surface temperatures are calculated in step 2 based on unsteady state heat balance calculation including 3-dimentional radiation and 1-dimentional conduction calculations. Based on outcomes in above 2 steps, CFD analysis is carried out one more time and more accurate results will be obtained.

Case Design and Boundary Conditions. Based on the whole summer meteorological data from the TMY (typical meteorological year), 24-hour meteorological data are averaged per day to get mean daily data. Consequently, the whole summer mean data are obtained by averaging the cumulated mean daily data. Finally, analysis date is determined by choosing the day whose data are most close to the whole summer mean data (calculating standard deviations by mean daily data and the whole summer mean data). Therefore, 14th July in Guangzhou is selected as a typical day of summer. Analysis time is selected based on at the time when maximum temperature occurred during analysis date, so 15:00 is selected in this study.

To avoid the lateral influence, the standard area was chosen in the center of simulated cases (Fig.5), and each building unit is $15 \mathrm{~m}$ high, $15 \mathrm{~m}$ long and the standard area is set into 2 parts to evaluate the outdoor thermal environment, the piloti area and non-piloti area. The piloti ratio of each case is set to be $0,40,60,80$ and 100 percent.

\section{Results and Analysis}

Air temperature. The average air temperature under piloti and non-piloti space is shown in Fig. 6 and 7. Both of air temperature under piloti and non-piloti area has some fluctuations, and no big temperature difference exists between piloti and non-piloti area (average $0.6{ }^{\circ} \mathrm{C}$ ). 


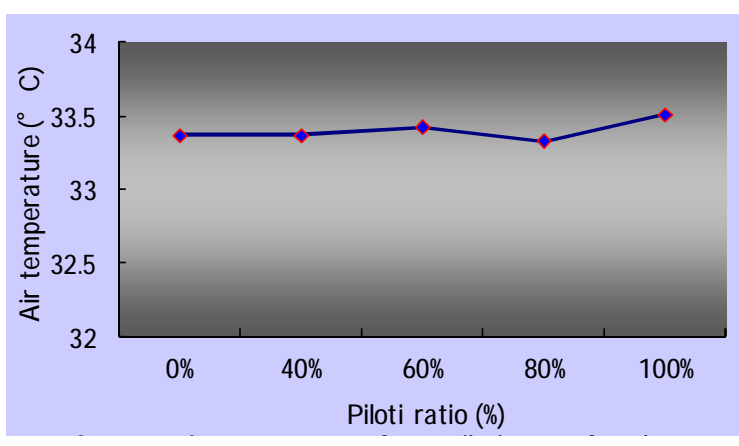

Fig. 6 Average air temperature of non-piloti area

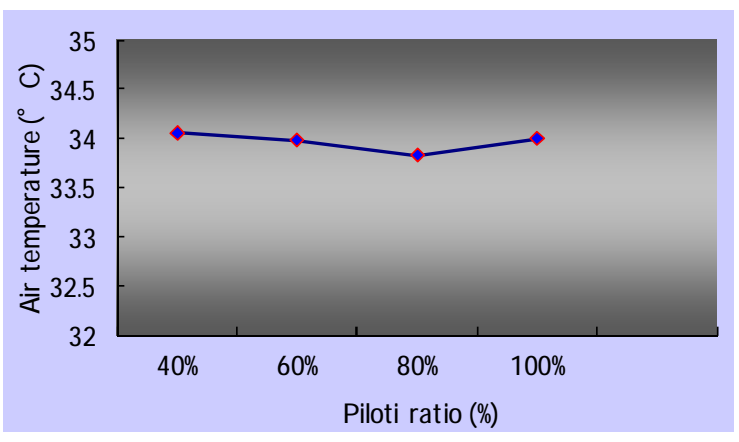

Fig.7 Average air temperature of piloti area

Wind velocity. The average wind velocity under piloti and non-piloti space is shown in Fig. 8 and Fig.9. It shows that, the lowest wind velocity of non-piloti area is about $1.2 \mathrm{~m} / \mathrm{s}$, which is much higher than that of piloti area $(0.2 \mathrm{~m} / \mathrm{s}, 40$ percent piloti ratio), and this should be due to the wind channel influence between building units. At the point of 60 percent piloti ratio, the slope of non-piloti area changed, which means the wind velocity of non-piloti area begins to increase faster. For the piloti area, the slope becomes gentle after 80 percent piloti ratio, indicating a lower increase speed.

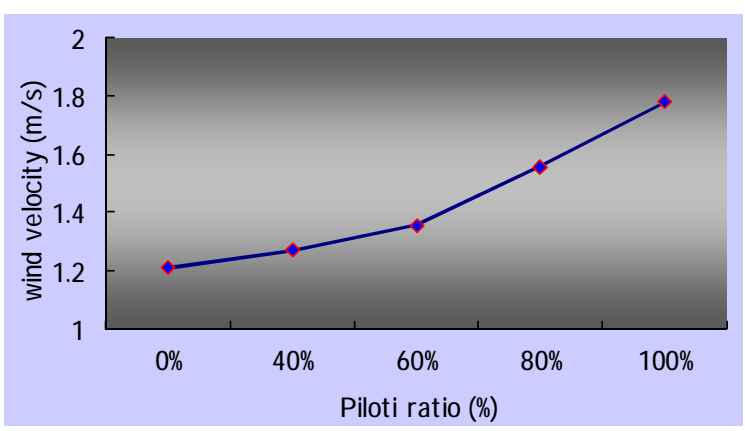

Fig. 8 Average wind velocity of non-piloti area

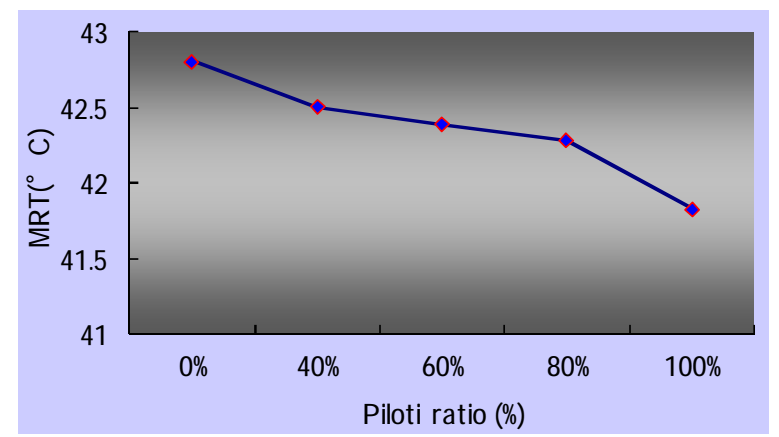

Fig. 10 Average MRT of non-piloti area

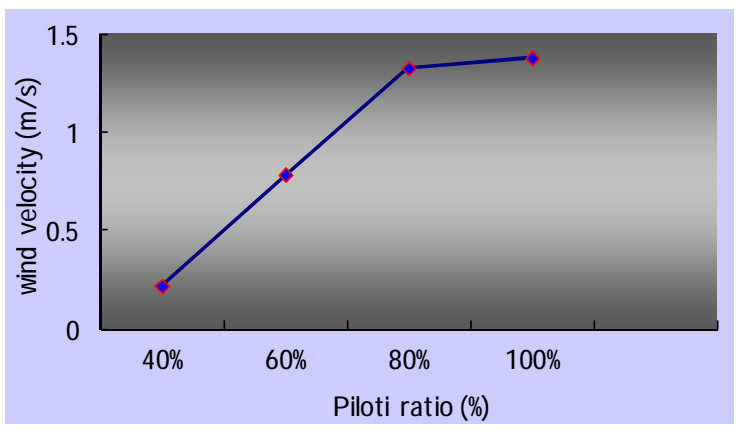

Fig.9 Average wind velocity of piloti area

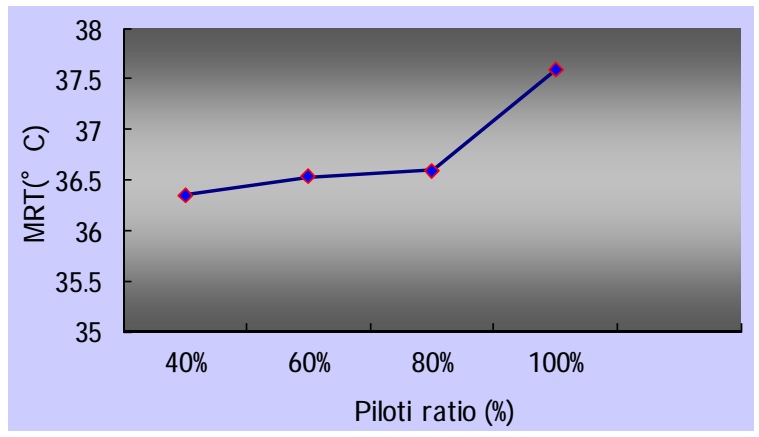

Fig.11 Average MRT of piloti area

Mean radiant temperature. The mean radiant temperature under piloti and non-piloti space is plotted in Fig. 10 and Fig.11. The MRT of non-piloti area decreases with increase of piloti ratio, which should be due to less radiation reflections received from surrounding walls, and when piloti ratio changes from 80 percent to 100 percent, the MRT of non-piloti area decreases faster. The MRT of piloti area increases along with the increases of piloti ratio, and this is because that, the area under piloti received more short-wave and long-wave radiations from sun and surrounding environment. When piloti ratio changes from 80 percent to 100 percent, the MRT under piloti area increases very fast, which is because the obstacle of side walls disappeared. 


\section{Conclusions}

By coupled simulation method, this work researched on the influence of piloti on outdoor residential communities in subtropical climate zones. The result shows that both of air temperature under piloti and non-piloti area fluctuated with piloti ratio changed, and a tiny air temperature difference was observed between these 2 areas.

The wind velocity was highly influenced by piloti, and the average wind velocity of non-piloti area changed from $1.2 \mathrm{~m} / \mathrm{s}$ to $1.8 \mathrm{~m} / \mathrm{s}$, accompanying with the wind velocity change from $0.2 \mathrm{~m} / \mathrm{s}$ to $1.4 \mathrm{~m} / \mathrm{s}$ of piloti areas. The average wind velocity inflection point of non-piloti area and piloti area is 60 percent and 80 percent piloti ratio, independently.

The MRT of non-piloti area decreases with increase of piloti ratio, and The MRT of piloti area increases along with the increases of piloti ratio. At the point of 80 percent, both of decreasing and increasing trend changed, showing a shaper slope in figures.

This result of this work is hoped to offer possible references for architects, urban planners, governments and researchers who may study on building environment, human thermal comfort and green and sustainable buildings.

\section{Acknowledgements}

This work was financially supported by the National Natural Science Foundation of China (Grant No. 51408160), China Postdoctoral Science Foundation (2015M571419), and the Project-sponsored by SRF for ROCS, SEM. Work partially supported by the Fundamental Research Fund for the Central Universities (HIT.NSRIF.2014 075), Harbin Science and Technology Bureau (2015RQQXJ068) and Heilongjiang Province Postdoctoral Science Foundation(LBH-Z15084).

\section{References}

[1] Yoshida Shinji, Murakami Shuzo and Narita Ken-ichi et al. Field Measurement of Outdoor Thermal Environment within Courtyard Canyon Space around Apartment Complex in Summer. Paper Collection of Plan System of Annual Meeting of Architectural Institute of Japan, No. 552, (2002), p.69-76

[2] Tetsu Kubota, Supian Ahmad: Wind Environment Evaluation of Neighbourhood Areas in Major Towns of Malaysia. Journal of Asian Architecture and Building Engineering, (2006), p.199-206

[3] Uehara Kiyoshi, Ymamao Yukio, Oikawa Susumu and Mochida Akashi: Wind-tunnel Experiments on Improving the Natural Ventilation of a Street-Canyon. Japan Society for Atmospheric Environment. 42 (5), (2007)

[4] Takanobu Moriizumi, Toru Kawai, Atsushi Inagaki, Manabu Kanda: Outdoor Urban Scale Model Experiments on the Effects of Building Height Variation on the Atmosphere. Paper Collection of Hydro Science and Hydraulic Engineering. Vol. 52, (2008)

[5] Yoshida Shinji, Murakami Shuzo, Mochida Akashi et al. Influence of Green Area Ratio on Outdoor Thermal Environment with Coupled Simulation of Convection, Radiation and Moisture Transport. Paper Collection of Planning System of Annual Meeting of Architectural Institute of Japan, No. 529, (2003), p.77-84

[6] Harayama Kazuya, Yoshida Shinji, Ooka Ryozo et al. Numerical Study Based on Unsteady Radiation and Conduction Analysis: Prediction of Outdoor Environment with Unsteady Coupled Simulation of Convection, Radiation and Conduction Part 1. Paper Collection of Planning System of Annual Meeting of Architectural Institute of Japan, No. 556, (2002), p.99-106

[7] Tianyu Xi, Qiong Li and Akashi Mochida: Research on Outdoor Climate and Thermal Comfort in Subtropical Climate Urban Areas: A Study in Guangzhou, China, as an Example. Summaries of 
Technical Papers of Annual Meeting of Architectural Institute of Japan, Environmental Engineering, (2011), p.805-806

[8] Tianyu Xi, Qiong Li, Akashi Mochida and Qinglin Meng: The Outdoor Thermal Environment and Thermal Comfort of Piloti in Subtropical Climate Cities. Journal of Habitat Engineering, Vol. 3 (2), (2011), p. $253-260$

[9] Tianyu Xi, Qiong Li, Akashi Mochida and Qinglin Meng: Study on the Outdoor Thermal Environment and Thermal Comfort around Campus Clusters in Subtropical Urban Areas. Building and Environment, Vol. 52, (2012), p.162-170

[10] Tianyu Xi, Qiong Li, Akashi Mochida and Qinglin Meng: A Study on the Influence of Various Human-built Elements on Outdoor Thermal Comfort in Subtropical Climate Cities. 4th International Conference on Human-Environment System, ICHES2011 in Sapporo, Japan, (2011), p.85-90

[11] Tianyu Xi, Jianhua Ding and Hongjin: Study on the Influence of Piloti on Mean Radiant Temperature in Residential Blocks by 3-D Unsteady State Heat Balance Radiation Calculation. Journal of Harbin Institute of Technology, Vol. 20 (4), (2014), p.91-95

[12]Tianyu Xi, Hong Jin and Jianhua Ding: Study on the Comprehensive Influence of Piloti Ratio on Mean Radiant Temperature in Residential Communities in Subtropical Climate Cities in China. 2015 International Conference on Materials Engineering and Environment Science, MEES2015 in Wuhan, China, (2015), p.478-485

[13]Tianyu Xi, Yingli Xuan and Akashi Mochida: Research on the Effects of Semi-open Space on the Outdoor Thermal Environment of Residential Communities in the Subtropical Zones: Simulation of Residential Communities in Guangzhou, China, as an Example. Technical papers of Annual Meeting of Society of Heating, Air-conditioning and Sanitary Engineers of Japan. (2009), p.405-408

[14]Tianyu Xi, Jianhua Ding and Hongjin: Study on Comprehensive Influence on Wind Environment of Piloti in Residential Blocks in Guangzhou, China. Global Conference on Civil, Structure and Environment Engineering, GCCSEE2016 in Guangzhou, China, (2016), to be published 